\title{
ABSTRACTS FROM OTHER JOURNALS
}

SURGICAL TREATMENT OF SPINALARTERIO-VENOUS MALFORMATION:

A. R. TAYlor. Proc. Soc. of British Neurol. Surgeons, 69th meeting, Aberdeen, 1964. F. Neurol. Neuro-surg. Psychiat. 27, 6, 578-9.

A report on six operation-cases of spinal angioma.

Removal of the angioma in the first two cases led to good motor-recovery, but to posterior column damage. In the next four cases the angiomata lay on the posterior surface of the cord. They had only one large arterial vessel feeding the lesion, unidirectional blood-flow, and, presumably, only one arterio-venous shunt.

The feeding vessel was clipped and only clearly extramedullary loops which might produce compression were removed.

Recovery after operation was almost complete in one case with only two years of neurological symptoms, three further cases improved partially, one patient died after mitral valvotomy.

The author concludes that this less radical procedure promises better results than total removal of the angioma with its dangers to the blood-supply of the cord.

Results will be best in cases of early diagnosis and operation.

P. HARRIS

\section{INTENSIFICATION OF THE EXCRETORY UROGRAM BY CONTINUOUS INFUSION OF CONTRAST MATERIAL: WHITESEL, J. A. \& HELLER, E. (I964). f. Urol. 92, 224-229.}

The authors refer to the findings of McChesney and Hoppe to the effect that the contrast medium known as Hypaque (Sodium Diatrizoate) is filtered by the glomeruli, its clearance being similar to those of inulin. In the case of reduced glomerular function only a small portion of the medium is filtered from the blood stream with a resulting poor visualisation. In order to compensate for the deficiency, the authors have tried successfully to obtain a better concentration by an intravenous drip lasting for 30 minutes.

A drip of $90 \mathrm{ml}$. of undiluted 50 per cent. Hypaque Sodium is put up and approximately $2 \mathrm{ml}$. infused as a test dose for adverse reaction. If there are none, an additional $30 \mathrm{ml}$. is infused over a period of 30 to 50 seconds and followed by a slow drip of 60 drops per minute. Although $90 \mathrm{ml}$. were sufficient in most cases, as much as $150 \mathrm{ml}$. was used in some cases with a poor renal function.

The authors used their 'intensification urography' in 70 patients, varying from normal to severely diseased patients. Intensification urography with normal renal function show little improvement on the conventional one, but in an obstructed kidney and reduced function better visualisation was obtained and retrograde pyelography obviated. No significant adverse effects were observed.

Cosbie Ross

CAUSE AND CORRECTION OF URETERAL REFLUX: HOWERTON, L. W. \& Lich, R., Jr. Amer. F. Urol., May 1963.

These authors emphasise the fact that vesical infection is responsible for vesico-ureteric reflux, and regard obstruction as a secondary factor. They advise control of infection to reverse the process from moderate to mild reflux and to prevent deterioration of renal function. A few more advanced cases may be suitable for reconstructive measures but those with evidence of gross renal damage require diversion of the urine.

Cosbie Ross 